\title{
O manual do professor de um livro didático de português: uma abordagem discursiva
}

\author{
The teacher's manual of a Portuguese textbook: \\ A discursive approach
}

\author{
Wesley Luis Carvalhaes* \\ wcarvalhaes@hotmail.com \\ Universidade Estadual de Goiás
}

\begin{abstract}
RESUMO: A presente pesquisa objetiva analisar o manual do professor de um livro didático de português (LDP) destinado ao trabalho com língua portuguesa no $9^{\circ}$ ano do ensino fundamental. Para a análise, o estudo baseia-se em contribuições teóricas dos estudos do discurso, por meio da apropriação de noções teóricas de Foucault (2010, 2012a, 2012b). A pesquisa apoia-se também em estudos sobre discurso e educação como os desenvolvidos por Popkewitz (1995), Veiga-Neto (2003) e Paniago (2005). Como principais conclusões, pode-se afirmar: a) que o manual do professor nos LDP configura-se como um espaço no qual se travam relações de poder que tomam o professor como alguém que precisa ser apoiado e conduzido em sua ação pedagógica; b) que o manual do professor, no LDP analisado, é construído com base no que prescrevem documentos oficiais sobre a elaboração de obras didáticas; nesse sentido, inscreve-se em uma ordem do discurso sobre o livro didático, caracterizada pelo controle do Programa Nacional do Livro Didático (PNLD) que, conforme Rangel (2015), tem cristalizado um modelo de produção do LDP.
\end{abstract}

PALAVRAS-CHAVE: Análise do Discurso. Livro didático de português. Manual do professor. Foucault.

ABSTRACT: This research aims to analyze the teacher's manual of a Portuguese Textbook (Livro didático de Português - LDP), targeted at ninth grade Portuguese students. The study is based on the theoretical contributions of discourse studies, especially notions developed by Foucault $(2010,2012 a, 2012 b)$. This study is also supported by research on discourse and education, such as those developed by Popkewitz (1995), Veiga-Neto (2003), and Paniago (2005). The main conclusions include that (a) the LDP teacher's manual may be seen as a space of power relationships, in which the teacher is regarded as someone who needs to be supported and guided throughout his teaching practices; (b) the LDP teacher's manual analyzed is produced according to official documents that prescribe the production of textbooks. Thus, this paper is about discourse on textbooks, which are controlled by the Nacional Textbook Program (PNLD), responsible for the crystallization of a model for Portuguese textbook production (RANGEL, 2015). .

KEYWORDS: Discourse analysis. Portuguese textbook. Teacher's manual. Foucault.

\footnotetext{
Doutor em Letras e Linguística (2016) pela Universidade Federal e Goiás. Mestre em Letras e Linguística (2009) pela mesma instituição. Atualmente é professor do quadro permanente da Universidade Estadual de Goiás/Campus Inhumas, atuando na área de língua portuguesa e linguística.
} 


\section{Introdução}

O livro didático de língua portuguesa (LDP) é um instrumento frequente no desenvolvimento das aulas de língua portuguesa na educação básica. Essa frequência faz com que o LDP se configure, segundo pontua Bittencourt (2004), como objeto de pesquisa de estudiosos de diversos campos do saber, especialmente aqueles que tomam o material didático como meio de investigação dos eventos de sala de aula.

O presente artigo, de caráter documental, com abordagem qualitativa, inscreve-se nesse grupo e objetiva analisar, à luz das contribuições foucaultianas, o manual do professor de um LDP. A importância da abordagem qualitativa, consoante à proposta por Goldenberg (2004, p. 50), "está relacionada à sua capacidade de possibilitar a compreensão do significado e a 'descrição densa' dos fenômenos estudados em seus contextos e não à sua expressividade numérica”. A perspectiva qualitativa, ao contrário de enfatizar a quantificação dos dados recolhidos, dá relevo e importância às informações que podem ser construídas com base em um olhar cuidadoso e crítico sobre determinado objeto.

No âmbito da abordagem qualitativa, há diversos métodos que permitem ao pesquisador a aproximação da realidade social com base no tratamento de seu objeto de investigação. Entre essas metodologias, está a pesquisa documental, que compreende a realidade por meio dos vários documentos que o ser humano produz. Para Bravo (2008), o documento diz respeito a tudo o que o ser humano cria, que se mostra como indício de sua ação, revelando suas ideias, seus valores e sua maneira de agir e de viver. Na mesma perspectiva, Cellard (2008) afirma que o documento constitui-se como fonte preciosa para o pesquisador, pois testemunha o modo como o ser humano configura determinada realidade.

Entendemos que o LDP é um documento que dá informações sobre o modo como os envolvidos na produção do material didático de língua portuguesa sistema de gestão governamental e equipe autoral - concebem a figura do professor. O manual do professor é elaborado segundo o que prescrevem documentos oficiais, como os que regulam o desenvolvimento do Programa Nacional do Livro Didático (PNLD). Nesse sentido, o LDP, e o manual que o acompanha, é escrito sob condições de produção determinadas. O manual do LDP, como a própria designação deixa claro, constitui-se como um espaço em que uma 
voz autorizada (a voz da equipe autoral) dirige-se a um interlocutor (o professor) que precisa de orientação sobre como o LDP deve ser utilizado e, consequentemente, sobre como deve ser desenvolvida a atividade pedagógica em que se usa determinado compêndio didático. Desse modo, com base nos postulados de Foucault (2012b), podemos afirmar que o manual constitui-se como um espaço em que se travam relações de poder as quais podem ser discutidas com base nos estudos do discurso de base foucaultiana.

Selecionamos um LDP da coleção didática Português: linguagens (CEREJA; MAGALHÃES, 2010). Essa coleção, conforme os dados disponíveis no endereço eletrônico do Programa Nacional do Livro Didático (PNLD), é mais adotada pelas escolas públicas estaduais de Goiânia no triênio 2011-2013 do PNLD para o trabalho com língua portuguesa no ensino fundamental. Optamos por analisar o volume do $9^{\circ}$ ano, pois as pequenas diferenças em relação aos volumes do $6^{\circ}, 7^{\circ} \mathrm{e}$ $8^{\circ}$ anos estão relacionadas apenas à mudança dos conteúdos específicos de cada um dos anos. A maior parte do manual, aquela que trata de questões teóricometodológicas e de orientações práticas para o professor, é a mesma nos quatro volumes.

Para a abordagem teórica do objeto, mobilizamos noções propostas por Foucault (2010, 2012a, 2012b), seguindo o caminho feito por outras pesquisas que se apropriam das contribuições foucaultianas para o desenvolvimento de estudos relacionados à educação, entre os quais ressaltamos os trabalhos de Popkewitz (1995), Veiga-Neto (2001) e Paniago (2005).

$\mathrm{Na}$ primeira parte deste artigo, discutimos os conceitos foucaultianos de discurso, enunciado e arquivo (FOUCAULT, 2010). Em seguida, apresentamos um breve percurso historiográfico sobre a produção didática no Brasil, pois, nesse percurso, delineiam-se as condições de produção do LDP analisado, pertencente ao triênio 2011-2013 do PNLD, e do manual que o acompanha. Na terceira parte, apropriando-nos das noções teóricas de Foucault (2010, 2012a, 2012b), procedemos a uma análise do manual, investigando as partes em que este se refere diretamente ao professor como interlocutor. Entendemos que o manual é um enunciado inscrito em uma ordem do discurso específica. Trata-se do discurso oficial sobre o livro didático, materializado em dois documentos governamentais: o guia do 
Programa Nacional do Livro Didático (PNLD) 2008, (BRASIL, 2007) e o edital para o processo de avaliação de coleções didáticas do PNLD 2014 (BRASIL, 2013) ${ }^{1}$.

\section{Bases teóricas}

Neste artigo, para o tratamento de nosso objeto, mobilizamos as noções foucaultianas de discurso, de enunciado e de arquivo. Para Foucault (2010), o conceito de discurso está articulado ao conceito de formação discursiva. Para o autor, discurso é "um conjunto de enunciados" que se apoiam na "mesma formação discursiva" (FOUCAULT, 2010, p. 132). Discurso, nessa acepção, refere-se a uma formação discursiva, ou seja, a uma sequência de enunciados articulados em razão de pertencerem ao mesmo espaço social e histórico em que são produzidos.

Foucault (2010), ao definir enunciado, afirma que este não é uma frase, uma proposição ou um ato de fala. $O$ enunciado é aquilo que dá possibilidade de existência a uma frase, a uma proposição, a um ato de fala. Assim, Foucault (2010) insere o enunciado na dimensão do discurso e não na dimensão da língua. A dimensão da língua diz respeito a estruturas que podem ser repetidas, enquanto a dimensão do discurso diz respeito a eventos comunicativos que, por seu caráter histórico e social, não podem se repetir. Desse modo, o discurso não é uma unidade formal, que pode ser repetida, mas um conjunto de enunciados cujas condições de existência podem ser observadas e mapeadas.

Os enunciados, portanto, devem ser analisados não pela sua linearidade formal, mas pela função enunciativa que lhes constitui como enunciados. $O$ realce à função enunciativa situa a língua como um meio de interação, por meio do qual o falante constitui-se na relação que estabelece, no seio social, com seu interlocutor e com o mundo.

Os conceitos de discurso, enunciado e arquivo são parte fundamental do projeto arqueológico foucaultiano que, conforme Revel (2011, p. 10), objetiva descrever como os saberes são determinados ao longo da história e como mantêm entre si uma correspondência na configuração de determinada lógica epistêmica. A

\footnotetext{
${ }^{1}$ É preciso esclarecer: escolhemos o guia do PNLD de 2008 (BRASIL, 2007), pois nele consta a coleção que analisamos, já que o guia do PNLD é enviado com antecedência para que as escolas adotem as obras referentes a determinado triênio. Escolhemos o edital do PNLD de 2014 (BRASIL, 2013) para mostrarmos como a ordem discursiva do triênio anterior do PNLD (2011-2013) determina como serão elaborados os LDP do triênio seguinte do mesmo programa.
} 
preocupação de Foucault, na fase arqueológica de seus estudos, volta-se para a descrição das condições que dão possibilidade de existência a determinados saberes (CASTRO, 2009).

Partindo dessa perspectiva arqueológica foucaultiana, a análise de um dado acontecimento discursivo - como a elaboração e a publicação de um LDP - deve ser feita pela descrição daquilo que é anterior ao acontecimento discursivo, ou seja, das condições históricas e sociais que permitem sua emersão e circulação. Para o desenvolvimento dessa descrição, ganham destaque os conceitos de enunciado e de arquivo.

O arquivo, segundo Gregolin (2004), é um conceito mais amplo, ao qual está hierarquicamente articulado o conceito de enunciado. Quando Foucault (2010) estabelece uma oposição entre a noção de enunciado e as noções de frase, proposição e ato de fala, põe em destaque o fato de que o enunciado não é uma unidade, como o são a frase, a proposição e o ato de fala, mas uma função. Essa função cruza diferentes estruturas e diversas unidades, fazendo com que os enunciados emerjam em determinado momento histórico e não em outro. Hoje, é possível o manual do professor ser entendido como um enunciado, por exemplo, pois há condições históricas e sociais que lhe permitem existir no LDP. O mesmo não acontece no início do século XIX, quando os LDPs, conforme os estudos de Soares (2001), não são acompanhados de um manual destinado ao professor.

Para Foucault (2010), o enunciado opera sempre quatro funções: 1) relaciona-se a outra materialidade - diversa ou idêntica à materialidade que se deseja conceituar como enunciado; 2) filia-se a um autor; 3) estabelece relação com outro(s) enunciado(s) em um mesmo campo associativo; 4) materializa-se de alguma forma. Para que um enunciado se materialize é necessária a operação de sistemas que permitem que um enunciado surja em determinado contexto e que circule socialmente. Esses sistemas constituem o arquivo, um conjunto de regras que permitem tanto a aparição de um enunciado quanto seu emprego em determinada situação. Situados nessa perspectiva de Foucault (2010), podemos fazer duas afirmações importantes.

A primeira é a de que o manual do professor do LDP analisado pode ser entendido como enunciado, pois atende às quatro condições pelas quais um enunciado se define. A relação com outra materialidade fica clara quando consideramos os outros manuais que circulam socialmente. Ora, um manual define- 
se, antes de tudo, pela dimensão utilitarista pela qual é criado. Se há necessidade de um manual, supõe-se que há um destinatário que dele precise para orientar-se em alguma atividade. A segunda condição relaciona-se à filiação a um autor. $O$ manual analisado tem um autor definido - o mesmo do LDP - que enuncia de um lugar socialmente autorizado. Como o manual apresenta-se como um encarte do LDP em questão, entendemos ser este manual parte integrante da elaboração do mesmo LDP.

O estabelecimento de um campo associativo, terceira condição, define-se pela relação que o manual estabelece com outros enunciados afins, entre os quais podemos citar as orientações oficiais para elaboração de material didático do PNLD (BRASIL, 2007, 2013) e os estudos acadêmicos que são feitos sobre o LDP. A quarta condição, existência material, realiza-se na elaboração e publicação do manual em uma obra didática.

Se o manual do professor no LDP define-se como enunciado, sua abordagem, em uma perspectiva foucaultiana, deverá considerar o arquivo que lhe possibilita a existência. Esse arquivo, do qual tratamos no próximo tópico, é o que define as condições de aparecimento e circulação do enunciado-manual, bem como o surgimento de outros enunciados a partir dele.

\section{O manual do professor em livros didáticos de português: condições de produção}

Pensar sobre as condições de produção do manual do professor em LDP é, antes de tudo, pensar nas condições de produção dele próprio. Não é nosso foco, neste texto, proceder a uma historiografia do livro didático (LD), mas alguns apontamentos históricos são fundamentais para que se entenda como a produção das obras didáticas atuais está associada à ação do governo.

A história do livro didático no Brasil, segundo Freitag et. al. (1989) e Oliveira et. al. (1984), como mostraremos a seguir, está intimamente associada à política governamental em relação ao livro didático. Embora não haja muitas fontes de pesquisa sobre a história do LDP, por meio da história do livro didático em geral e da de livros didáticos de outras áreas, como o trabalho de Amaral (2012), podemos chegar à história do LDP. 
Witzel (2002) é boa indicação de como esse percurso histórico pode ser feito: só é possível discorrer sobre a história do livro didático se o fazemos com base na consideração de sua política como apontado em Freitag et al. (1989).

A partir de 1937, ocorreram mudanças significativas no percurso referente à edição e circulação de livros didáticos, pois foi criado o Instituto Nacional do Livro Didático, o precursor do atual PNLD, órgão subordinado ao Ministério da Educação. Segundo observa Witzel (2002, p. 17), nessa época se consagrou o emprego do termo livro didático "entendido até os dias de hoje como sendo, basicamente, o livro adotado na escola, destinado ao ensino, cuja proposta deve obedecer aos programas curriculares escolares". Assim se definiu livro didático no Decreto-Lei $n^{\circ}$ 1.006, de 30 de dezembro de 1938, em seu Art. $2^{\circ}$ :

Compêndios são os livros que expõem total ou parcialmente a matéria das disciplinas constantes dos programas escolares; livros de leitura de classe são os livros usados para leitura dos alunos em aula; tais livros também são chamados de livro-texto, compêndio escolar, livro escolar, livro de classe, manual, livro didático (OLIVEIRA, 1980, p.12 apud OLIVEIRA et al., 1984, p. 22).

Essa definição "privilegia o aspecto da 'consagração' ou legitimação do livro no próprio processo de ensino; o livro didático é basicamente o livro adotado na escola" (OLIVEIRA et al., 1984, p.23). No escopo de nosso trabalho, essa definição fixa-se como um enunciado importante para a análise do manual em questão.

Além de apresentar a definição de livro didático, o Decreto-lei criou a Comissão Nacional do Livro Didático a cujos membros, indicados pelo governo, cabia, entre outras, a função de examinar, avaliar e julgar os livros didáticos, autorizando ou não seu uso nas escolas.

No caminho do controle governamental da produção didática, até o atual PNLD, há a criação e extinção de vários órgãos e programas. Conforme Freitag et al. (1989), em 1967, cria-se a Comissão do Livro Técnico e do Livro Didático (COLTED), extinta em 1971, com a criação do Programa do Livro Didático (PLID). Esse programa foi assumido, em 1976, por determinação de decreto presidencial, pela Fundação Nacional do Material Escolar (FENAME), criada em 1968. Antes de se tornar responsabilidade da FENAME, O PLID estava agregado ao Instituto Nacional do Livro (INL) - criado em dezembro de 1937 - subordinado ao Ministério da Educação (FREITAG et al. 1989). Em 1983, conforme Amaral (2012), é criada a Fundação Nacional do Estudante (FAE), em substituição à FENAME. Em 1985, é 
criado o PNLD cuja responsabilidade de execução, em 1997, com a extinção da FAE, é transferida para o Fundo Nacional de Desenvolvimento da Educação (FNDE).

Esse percurso é fundamental para descrevermos as regras de formação que possibilitaram a emergência do enunciado-manual do professor em LDP.

O LDP não é algo novo na atividade pedagógica dos professores do idioma materno. Soares (2001), por exemplo, evidencia essa afirmação ao construir uma história da leitura e da formação do professor-leitor por meio da análise de livros didáticos - no caso, A Antologia Nacional, de Fausto Barreto e Carlos de Laet, e Estudo dirigido de Português, de Reinaldo Mathias Ferreira.

Soares (2001) faz um contraponto analítico entre $A$ Antologia Nacional $^{2}$ obra que traz apenas textos, sem questões a eles relacionadas - e Estudo dirigido de Português que chega às escolas no início dos anos de 1970. Uma das constatações da autora é a de que, a partir dos anos de 1970, o LDP, além de excertos literários para serem trabalhados pelo professor nas aulas de português, começa a apresentar questões sobre esses textos e suas respostas correspondentes.

Essas questões, acompanhadas de suas respostas, constituem, mais tarde, uma seção comum nos LDP de hoje: o manual do professor. Conforme Bunzen e Rojo (2005), nos anos de 1970, com a democratização da escola e consequente aumento do número de alunos, surge a necessidade de aumentar o quadro de professores. Enquanto a academia não supre essa necessidade, cria-se um cenário que, em nossa perspectiva, ajuda a compreender o espaço que o LDP e, consequentemente, seu manual, ocupa em nossas salas de aula. Por um lado, ressaltam Bunzen e Rojo (2005), os professores já atuantes nas escolas, notadamente as públicas, assumem carga horária expandida; por outro lado, profissionais de outras áreas, sem o devido preparo, são nomeados professores.

É nesse contexto de democratização do ensino público que, segundo Batista (2004), ao assumir a função de organizar a atividade docente, o livro didático passa a precisar de um manual que apresente orientações práticas direcionadas ao professor, ocupando-lhe o lugar: "sua sequência [do manual do professor] torna-se a sequência das aulas e sua realização passa a marcar o tempo escolar. [...] é um

${ }^{2}$ Publicada pela primeira vez em 1895 , foi uma das compilações literárias mais usadas pelos estudantes que passaram pela escola secundária, atingindo, em 1969, sua $43^{a}$ edição. 
livro, mas é também o caderno de exercícios, a voz do professor, o planejamento, a progressão das aulas" (BATISTA, 2004, p. 58).

Essa centralidade ocupada pelo manual do professor na elaboração de um LDP, pelo menos daqueles a serem comprados pelo governo, hoje, é oficial. Em nossa pesquisa, não conseguimos precisar o ponto exato em que o manual começa a ser um critério para que uma obra figure no Guia de Livros Didáticos do PNLD. Entretanto, pudemos perceber que esse requisito fica bastante claro no guia de 2008:

O Manual do Professor é uma peça chave para o bom uso do Livro Didático. Um manual adequado deve ao menos explicitar a proposta didático-pedagógica que apresenta, descrever a organização interna da obra e orientar o docente em relação ao seu manejo. É desejável, ainda, que explicite seus fundamentos teóricos e que indique e discuta, no caso de exercícios e atividades, as respostas esperadas. É com um bom Manual do Professor, portanto, que o LD cumpre mais adequadamente sua função de formação pedagógica específica [...] (BRASIL, 2007, grifos do autor).

Esse excerto revela a importância que um programa do governo, como principal consumidor de obras didáticas, dá ao fato de um livro didático apresentar um manual destinado ao professor. Ao afirmar que um manual adequado (há, portanto, manuais inadequados) "deve ao menos explicitar a proposta" didáticopedagógica sobre a qual o livro é elaborado, põe-se em evidência uma imagem específica do destinatário: sugere-se a constituição de um professor mal formado que, em contato com as atividades do livro, não é capaz de identificar as perspectivas teórico-metodológicas subjacentes às questões. Para além disso, esse docente de que trata o guia é alguém que necessita da ajuda do manual no que concerne ao manejo do próprio livro e, consequentemente, à elaboração e ao desenvolvimento de suas aulas. Em outras palavras, está objetivado, nesse enunciado, um professor cuja ação pedagógica não é autônoma, mas dependente.

Como vimos, a produção e circulação do livro didático e, por extensão, a do LDP, está intimamente ligada à ação reguladora do governo. O surgimento do manual do professor em LDP é reflexo de condições de produção socialmente marcadas e historicamente construídas pelo discurso oficial sobre o livro didático. As demandas da democratização da escola pública ocasionaram, conforme vimos, a 
situação de centralidade do LDP e, consequentemente, de seu manual na atividade docente.

As políticas públicas para o livro didático, em nossa perspectiva, em uma leitura das ideias de Foucault (2010), constituem o arquivo do qual emerge o enunciado-manual do professor, o qual se inscreve em uma ordem do discurso oficial sobre a produção do livro didático (FOUCAULT, 2012a) da qual passamos a tratar na análise proposta no próximo tópico.

\section{0 manual do professor: enunciado inserido em uma ordem discursiva}

No LDP analisado, além das respostas às questões propostas para o trabalho pedagógico com o ensino de língua materna, as quais aparecem no corpo principal do livro, há, para o professor, ao final da obra, um manual, que se constitui como o objeto de estudo desse trabalho. Nesse manual, segundo os autores, apresentam-se os pressupostos teóricos que orientaram a elaboração do LDP, o que, como já apontamos, é uma exigência do guia do livro didático (BRASIL, 2007).

Essa exigência é reiterada pelo edital de convocação para inscrição e avaliação de coleções didáticas para o PNLD 2014: "a) O manual do professor deve conter instruções e orientações teórico-metodológicas ao professor, acompanhadas do livro do aluno de forma integral, com ou sem comentários adicionais" (BRASIL, 2013, p. 22). A coleção didática que deseja ser avaliada pelo PNLD deve contar com um manual do professor, cuja estrutura está delineada em documentos como o edital em questão e o guia do programa.

Esses documentos revelam relações de poder. Foucault (2012a) nos fala de um poder que se exerce mesmo sem ter como ponto de origem um titular específico e relaciona esse mesmo poder ao modo como se ordenam os discursos em determinado grupo social. Existe um controle, uma seleção, uma organização e uma redistribuição na produção discursiva já que "o discurso não é simplesmente aquilo que traduz as lutas ou os sistemas de dominação, mas aquilo porque, pelo que se luta, o poder do qual nos queremos apoderar" (FOUCAULT, 2012a, p. 10). Aqui se delineia a noção de discurso como prática social, como acontecimento condicionado por possibilidades e regras pré-determinadas.

Nesse sentido é que tomamos o enunciado-manual do professor, entendendo que, no LDP analisado, o manual materializa um discurso no qual há 
duas posições claramente marcadas: a voz do manual (dos autores do LDP) que, inscrita na ordem do discurso oficial sobre a produção do livro didático, dirige-se ao professor, tomando-o como alguém que precisa de orientação e tutela. Nesse sentido, é interessante o trabalho de Barbosa (2000) que, ao pesquisar sobre a imagem do professor suposto nos Parâmetros Curriculares Nacionais (PCNs), chega a estabelecer um distanciamento entre a imagem do professor nos PCNs e o professor concretamente situado na realidade. Obviamente, em nossa análise, é preciso ressaltar que, como uma obra selecionada para figurar no Guia do PNLD, além do professor, como usuário final, o manual também tem como destinatário os avaliadores do PNLD.

Para a análise, escolhemos o PNLD de 2010, do triênio 2011-2013 do PNLD. O manual analisado (CEREJA; MAGALHÃES, 2010), de 32 páginas, dividese estruturalmente em introdução; estrutura e metodologia da obra; cronograma; leitura extraclasse; produção de texto; ensino de língua; avaliação e plano de curso.

Em cada uma dessas partes, os autores apresentam, minuciosamente, aspectos técnicos e orientações teórico-metodológicas aos professores, adequandose, inclusive, ao que determina o edital do PNLD 2014 sobre a identificação do manual, que será excluído da avaliação caso "apresente na frente da folha de rosto outros elementos (textos ou ilustrações) além da expressão 'Manual do Professor' em local e tamanho de fácil identificação" (BRASIL, 2013, p. 32). Aqui, tanto o documento oficial quanto o manual analisado configuram-se como espaços em que se travam relações de poder.

Conforme Paniago (2005), na perspectiva foucaultiana, o poder é pensado como relação. Ao analista, importa descrever o modo como o poder é exercido e as direções em que esse exercício se dá. Para Foucault (2012b), os modos de organização de uma sociedade podem ser divididos em: a) sociedade de soberania - em que poder é exercido por um rei ou senhor, por meio de atos gerais e externos de vigilância; b) sociedade disciplinar - na qual as instituições são dispositivos de visibilidade e sociedade de controle, designação usada por Deleuze (1992) que caracteriza a implementação de um novo regime de dominação, quando o poder é exercido à distância.

$\mathrm{Na}$ análise do enunciado-manual do professor, fica claro que os autores se adequam ao que deles se espera e, no manual, deixam evidente ao professor o que é dele esperado. Em outras palavras, os autores subjetivam-se ao elaborar o manual 
como é prescrito pelo governo; do mesmo modo, objetivam o professor, ao produzir o manual. Não é intenção desse artigo discutir a subjetivação e/ou a resistência do professor ante a objetivação evidenciada no manual analisado, tarefa que deixamos para outro estudo. O que nos importa é tratar da configuração do manual analisado, pois entendemos que, nesse enunciado, evidenciam-se relações de poder (FOUCAULT, 2012b) as quais se dão por meio da inscrição do enunciado-manual do professor em uma ordem discursiva específica (FOUCAULT, 2012a).

Logo no início do manual analisado, há dois trechos nos quais as relações de poder entre autor e professor ficam muito claras:

Esta coleção chega à sua $6^{a}$ edição, revista, ampliada e atualizada. Desde a $1^{a}$ edição, a obra tem sido acolhida com entusiasmo por um grande número de professores que reconhecem a possibilidade concreta de, com o apoio dela, transformar sua prática no ensino de língua portuguesa. [...] Se os professores que fizeram uso das edições anteriores desta coleção notaram um avanço significativo em seu trabalho, entendemos que é possível ir além (CEREJA; MAGALHÃES, 2010, p. 2).

Ao ressaltarem a visão apreciativa sobre a coleção didática, os autores ressaltam o lugar que ocupam em relação ao lugar do professor. Se um grande número de professores recebe "com entusiasmo a obra", cria-se uma expectativa positiva da recepção do LDP por parte de todo professor que com ele tomar contato. Essa apreciação positiva deve-se ao fato de que a obra é um "apoio" ao professor que pode ter sua prática de ensino "transformada". Tem-se aqui, claramente delineada, a imagem de um professor que precisa de ajuda, de tutela. Nesse aspecto, o manual, alinha-se ao discurso oficial:

O manual do professor deve se constituir em um material diferenciado do livro do aluno e deve visar à orientação dos docentes para o uso adequado da coleção, constituindo-se, ainda, num instrumento de complementação didático-pedagógica e atualização para o docente. Nesse sentido, o livro deve organizar-se de modo a propiciar ao docente uma efetiva reflexão sobre sua prática (BRASIL, 2013 , p. 56).

A necessidade de orientação supõe um docente que não consegue, por si, conduzir a sua prática. Essa interpretação reporta-nos aos trabalhos de Batista (2004), Bunzen e Rojo (2005) e Amaral (2012), quando apontam possíveis razões para o surgimento, em meados dos anos de 1970, de manuais do professor nos 
livros didáticos. Conforme esses estudos, o manual surge, nesse contexto, como tentativa de se preencherem lacunas na formação dos professores e como meio de instrumentalização para o ensino de profissionais sem formação em licenciatura. 0 discurso oficial sobre a produção didática, como se vê em Brasil (2007; 2013), assimila essa perspectiva, de modo que os livros didáticos atuais, desde que queiram ser avaliados pelo PNLD, o principal consumidor de obras didáticas, devem apresentar manuais do professor, conforme as prescrições do governo.

Essa situação, a nosso ver, ilustra bem o que Popkewitz (1995, p. 175) afirma: "as práticas linguísticas dos campos disciplinares envolvem certas regras de expressão e censura do significado, que atuam através da produção de signos e sistemas de significação". A elaboração do manual do professor é uma produção ligada às práticas linguísticas de um campo disciplinar específico, o campo do discurso oficial do governo que, por meio do PNLD, constitui signos específicos, como a concepção do professor como alguém que precisa de apoio no desenvolvimento de sua atividade profissional. Nesse sentido, o PNLD, segundo Rangel (2015), constitui uma ordem do discurso sobre a produção e elaboração do LDP, conduzindo à cristalização de um modelo de livro didático.

No manual analisado, as várias seções constituem-se por textos explicativos com forte apelo instrucional. Desse modo, o LDP cumpre o que dele espera o PNLD. Essa perspectiva instrucional assumida pelo manual, em consonância ao que exige o discurso oficial, chega ao ponto de indicar ao professor que utiliza o livro o número de aulas adequado para que se trabalhe cada unidade ${ }^{3}$ da obra:

Desse modo, teríamos 36 semanas e um total bruto de 180 aulas. Descontando $20 \%$ para avaliações e feriados, podemos calcular uma média de 37 aulas por bimestre, assim distribuídas, de acordo com os conteúdos a serem trabalhados em cada unidade: Abertura - 1 aula; Capítulo $1-11$ aulas; Capítulo $2-11$ aulas; Capítulo $3-11$ aulas; Intervalo - 3 aulas (CEREJA; MAGALHÃES, 2010, p. 8).

Essa proposta de organização do trabalho docente sugere que o professor limita sua ação pedagógica ao manuseio do LDP, reproduzindo o que nele é proposto. Além disso, sugere-se que o professor não consegue gerir o próprio tempo, necessitando, para isso, da ajuda do material didático. Se o LDP está assim

\footnotetext{
${ }^{3} \mathrm{O}$ livro analisado é composto por quatro unidades, correspondentes aos quatro bimestres em que habitualmente se organiza o ano letivo. Essas unidades se subdividem em cinco partes: abertura, três capítulos de estudo e um projeto de trabalho extraclasse denominado "intervalo".
} 
elaborado para atender às orientações do PNLD, temos aí relações de poder que podem ser mapeadas. O governo, pelo discurso oficial, exerce poder sobre os autores/editoras de livros didáticos, que o exercem sobre o professor, que, por sua vez, o exerce sobre o aluno. Esse exercício do poder não é unilateral, não parte de um ponto central, e pode ser descrito pelas micropráticas de poder estabelecidas no cotidiano. Entretanto, chama a nossa atenção, neste estudo, o modo como o manual analisado, ao materializar o discurso oficial sobre como se deve elaborar um manual de livro didático, evidencia a noção de sociedade disciplinar da qual trata Foucault (2012b).

Nessa forma de governo, o indivíduo é sujeito ao tempo, o que o faz produzir com o máximo de eficiência e rapidez. No manual analisado, a divisão do número de aulas para cada unidade dirige o trabalho do professor, esperando que este organize sua prática conforme orienta o LDP, cuja elaboração, por sua vez, está condicionada ao que prescreve o PNLD. Tem-se aqui um exemplo claro da noção de governamentalidade, proposta por Foucault (2012b), como um conjunto de técnicas por meio das quais o governo é exercido, como uma designação para a atividade que rege o modo como as pessoas devem se comportar em determinado contexto.

Para além das orientações e instruções, o manual define como deve se comportar o professor, por exemplo, em relação à leitura:

O ideal é que o professor seja um bom leitor e que esteja sempre atualizado em relação a novas publicações. Cabe a ele proporcionar às crianças e aos adolescentes um convívio estimulante com a leitura, assim como possibilitar que esta cumpra o seu papel, que é o de ampliar, pela leitura da palavra, a leitura do mundo (CEREJA; MAGALHÃES, 2010, p. 8).

Pensamos ser um consenso a ideia de que um professor de língua portuguesa seja, sobretudo, um bom leitor. O que nos intriga é o fato de um manual destinado ao trabalho docente considerar "ideal" a condição de bom leitor do professor, afastando-a, portanto, das situações reais. Está aí configurado um professor de língua portuguesa que não lê e que, consequentemente, tem dificuldades em desenvolver sua prática, sendo necessário, por isso, que o manual colabore "para que o processo de ensino-aprendizagem acompanhe avanços recentes, tanto no campo de conhecimento do componente curricular da coleção, quanto no da pedagogia e da didática em geral" (BRASIL, 2013, p. 57). 
Conforme o edital do PNLD, o manual do professor de um livro didático deve, entre outras atribuições, "orientar o professor para o uso adequado da coleção, inclusive no que se refere às estratégias e recursos de ensino a serem empregados" (BRASIL, 2013, p. 57). O manual analisado, em muitos trechos, traz "sugestões" bem pontuais:

[...] propor que os alunos tenham um caderno especial para a produção de textos; [...] escolher uma dia especial para a produção de texto; [...] favorecer a desinibição, encorajar a expressão espontânea, estimular a fluência de ideia, criar o respeito mútuo, valendo-se de situações que levem os alunos a expressarem-se oralmente. Nesse sentido, por exemplo, pode-se pedir que cada aluno leia sua produção de texto para os colegas. [...] criar situações em que a produção de texto seja socializada, isto é, um colega ou o grupo sugere modificações para que 0 autor do texto proceda à reescritura (CEREJA; MAGALHÃES, 2010, p. 8).

Nesse trecho, evidencia-se algo que está presente em todo o manual analisado: as orientações dirigem-se a um professor que não tem a formação necessária para desenvolver bem o ensino de língua portuguesa (no caso, especificamente, o ensino de redação). As sugestões subestimam o docente a quem o LDP se destina, mas, além disso, atribuem-lhe tarefas hercúleas que, a nosso ver, não estão necessariamente ligadas à atividade docente. O professor deve "criar" o respeito mútuo entre os alunos? É possível criar o respeito? Parece-nos, aqui, mais uma vez, que o manual enuncia aquilo que pode (e deve) enunciar em uma ordem discursiva específica; aquilo que está determinado no edital do PNLD quando afirma que também é uma tarefa do livro didático contribuir com o trabalho do professor na "formação dos alunos como cidadãos, de modo que possam estabelecer julgamentos, tomar decisões" (BRASIL, 2013, p. 53).

Não queremos negar que seja a escola um espaço de trabalho para a construção da cidadania, mas parece-nos perigoso que ao professor seja delegada tão grande parcela de responsabilidade nesse trabalho cujo possível fracasso também pode ser atribuído ao professor. O manual analisado diz o que pode/deve dizer, já que, em toda sociedade, "a produção do discurso é ao mesmo tempo controlada, selecionada, organizada e redistribuída por certo número de procedimentos" (FOUCAULT, 2012a, p. 8), cuja função é determinar o que pode e o que não pode ser dito, enunciado. 
Por meio da análise que propomos, o que se ressalta é a adequação do enunciado-manual do professor à ordem discursiva de que faz parte, materializada no edital do PNLD (BRASIL, 2013) e no guia do PNLD de 2008 (BRASIL, 2007), configurando o que afirma Foucault (2012a) sobre a ordem que é inerente ao discurso e como este instaura práticas e ações sociais determinadas.

\section{Conclusão}

Começamos este artigo tratando das noções de discurso, enunciado e arquivo para Foucault $(2010,2012 b)$, por considerar que esses pressupostos teóricos possibilitam o tratamento do objeto que aqui analisamos. Tomando o manual do professor como um enunciado, possível a partir de um conjunto de enunciados, de um arquivo, entendemos que o enunciado-manual do professor inscreve-se em uma ordem do discurso que determina um modelo de livro didático a ser produzido. Nesse discurso, tomam forma relações de poder (FOUCAULT, 2012b), materializadas pelo alinhamento do enunciado-manual do professor a outros enunciados próprios do discurso oficial sobre o livro didático como o guia do PNLD 2008 (BRASIL, 2007) e o edital para avaliação de coleções didáticas para o PNLD 2014 (BRASIL, 2013).

Demonstramos, por meio de breve recuperação da história do livro didático no Brasil, que, desde os primeiros anos do século XX, a produção didática brasileira está relaciona ao controle do governo, o que lhe dá feições particulares. Desse modo, a ação dos documentos oficiais constitui-se como a principal condição de produção do material didático e, por extensão, do material didático para o ensino da língua portuguesa.

Por meio de nossa análise do enunciado-manual do professor de um LDP específico, percebemos que este adequa-se ao que prescreve o governo por meio dos documentos que definem o que pode e deve ser enunciado.

Desse modo, o material didático assume um lugar de destaque, passando a nortear a atividade docente, fixando-se como referencial tanto de métodos e técnicas de ensino, quanto de conteúdos e atividades.

Cabe ao professor - o que certamente é tema para outro estudo - aceitar o que lhe prescreve o LDP ou resistir a esse discurso que o toma como um profissional que precisa ser conduzido e orientado em sua prática. Salienta-se, ao 
fim deste artigo, a importância dos pressupostos teóricos foucaultianos para o desenvolvimento de estudos sobre situações sócio-historicamente situadas como a produção do LDP e seu emprego no ensino de língua portuguesa. O percurso investigativo foucaultiano, portanto, pode ser útil a quem deseja compreender os acontecimentos discursivos relacionados aos eventos escolares e à atuação do professor de língua materna.

\section{Referências}

AMARAL, Sandra Regina Rodrigues do. Significações do professor de história para sua ação docente: o livro didático de história e o manual do professor do segundo segmento do ensino fundamental no PNLD 2008. 2012. 144p. Dissertação (Mestrado em Educação) - Departamento de Educação, Universidade Estadual de Londrina, Londrina, 2012.

BARBOSA, Jacqueline P. Do professor suposto pelos PCNs ao professor real de língua portuguesa: são os PCNs praticáveis?. In: ROJO, Roxane H. (Org.). A prática de linguagem em sala de aula: praticando os PCNs. São Paulo: EDUC: Campinas: Mercado de Letras, 2000, p.149-82

BATISTA, Antônio Augusto Gomes. Um livro didático "moderno". In: escolar: uma história. Belo Horizonte: CEALE/Autêntica, 2004. p. 35-68. . O texto

BITTENCOURT, Circe Maria Fernandes. Em foco: história, produção e memória do livro didático. Educação e Pesquisa. Revista da Faculdade de Educação da USP, São Paulo, pp. 471-473, set/dez, 2004.

BRASIL. Ministério da Educação; Secretaria de Educação Básica. Guia de livros didáticos - PNLD 2008 - Anos finais do Ensino Fundamental. Brasília: MEC, 2007. Disponível em: http://www.fnde.gov.br/programas/livro-didatico/guia-do-livro/item/ 2347 -guia-pnld-2008 \%E2\%80\%93-anos-finais-do-ensino-fundamental. Acesso em: 24 abr. 2017.

Ministério da Educação; Secretaria de Educação Básica. Edital de convocação para o processo de inscrição e avaliação de coleções didáticas para o Programa Nacional do Livro Didático-2014. Brasília: MEC, 2013. Disponível em: http://www.fnde.gov.br/programas/livro-didatico/livro-didatico-editais. Acesso: em 24 abr. 2017.

BUNZEN, Clécio; ROJO, Roxane. Livro didático de língua portuguesa como gênero do discurso: autoria e estilo. In: COSTA VAL, Maria da Graça; MARCUSCHI, Beth. (Org.). Livro didático de língua portuguesa: letramento e cidadania. Belo Horizonte: CEALE/Autêntica, 2005. p. 73-113.

BRAVO, Sierra R. Técnicas de investigacion social: teoría y ejercicios. 14 ed. Madrid: Thompson, 2008. 
CASTRO, Edgardo. Vocabulário de Foucault - Um percurso pelos seus temas, conceitos e autores. Trad. Ingrid Müller Xavier. Belo Horizonte: Autêntica, 2009.

CELLARD, André. A análise documental. In: POUPART, Jean. et al. A pesquisa qualitativa: enfoques epistemológicos e metodológicos. Trad. Ana Cristina Nasser. Petrópolis: Vozes, 2008. p. 295-316.

CEREJA, Willian Roberto; MAGALHÃES, Thereza Cochar. Português: linguagens. $9^{\circ}$ ano. 6. ed. ref. São Paulo: Atual, 2010.

DELEUZE, Giles. Post-scriptum sobre as sociedades de controle. In: Conversações. Trad. de Peter Pál Pelbart. Rio de Janeiro: Ed. 34, 1992. p. 219-226.

FREITAG, B. et al. O livro didático em questão. Col. Educação Contemporânea. São Paulo: Cortez, 1989.

FOUCAULT, Michel. A arqueologia do saber. Trad. Luiz Felipe Baeta Neves. 7. ed. Rio de Janeiro: Forense Universitária, 2010.

A ordem do discurso: aula inaugural no Collège de France, pronunciada em 2 de dezembro de 1970. Trad. Laura Fraga de Almeida Sampaio. 22. ed. São Paulo: Loyola, 2012a.

$2012 b$.

Microfísica do poder. Trad. Roberto Machado. 25. ed. São Paulo: Graal,

GOLDENBERG, Mirian. $A$ arte de pesquisar: como fazer pesquisa qualitativa em Ciência Sociais. 8. ed. Rio de Janeiro: Record, 2004.

GREGOLIN, Maria do Rosário Valencise. O enunciado e o arquivo: Foucault (entre)vistas. In: SARGENTINI, Vanice; NAVARRO-BARBOSA, Pedro (Org.). Foucault e os domínios da linguagem - discurso, poder, subjetividade. São Carlos, SP: Claraluz, 2004. pp. 22-44.

OLIVEIRA, João Batista Araújo et al. A política do livro didático. São Paulo: Unicamp, 1984.

PANIAGO, Maria de Lourdes F. S. Práticas discursivas de subjetivação no contexto escolar. 2005. 344p. Tese (Doutorado em Linguística e Língua Portuguesa) Faculdade de Ciências e Letras, UNESP/Araraquara, Araraquara, 2005.

POPKEWITZ, Thomas. História do currículo, regulação social e poder. In: SILVA, Tomaz Tadeu da. (Org.). O sujeito da educação: estudos foucaultianos. 2. ed. Petrópolis: Vozes, 1995. p. 173-210.

RANGEL, Egon de Oliveira. Livro didático de Língua Portuguesa para a Educação Básica: problemas e perspectivas. In: BUNZEN, Clécio. (Org.). Livro didático de português: políticas, produção e ensino. São Carlos, SP: Pedro e João Editores, 2015. p. 17-38. 
REVEL, Judith. Dicionário Foucault. Trad. Anderson Alexandre da Silva. Rio de Janeiro: Forense Universitária, 2011.

SOARES, Magda. O livro didático como fonte para a história da leitura e da formação do professor-leitor. In: MARINHO, Marildes. (Org.). Ler e navegar: espaços e percursos da leitura. Campinas, SP: Mercado das Letras, 2001. p. 31-76

VEIGA-NETO, Alfredo. Foucault e a educação. Belo Horizonte: Autêntica, 2003.

WITZEL, Denise Gabriel. Identidade e Livro Didático: Movimentos identitários do professor de Língua Portuguesa. 2002. 175p. Dissertação (Mestrado em Linguística Aplicada). Universidade Estadual de Maringá, Maringá, 2002.

Recebido em 28/12/2017

Aceito em 22/04/2018

Publicado em 01/05/2018 